\title{
EDITORIAL
}

\section{Changes in JINS}

This marks the official beginning of my tenure as Editorin-Chief of JINS though the transition has been ongoing for more than a year. The change you will notice most is the cover, but I have also instituted a new section, Neurobehavioral Grand Rounds, which is a way to emphasize the importance of case studies by including an introduction by an expert in the field who will put the case in a broader context. Other sections will remain the same except I have changed the name of Research Letters to Rapid Communications, and I want to encourage you to submit such papers that are short, and are put on a fast track for review. Electronic submission and review is still in its infancy, but I am optimistic that it will speed the review process. Speedy publication is in all of our interests, but rapid, high quality reviews are the cornerstone of that speed. Therefore, when JINS asks you to review a manuscript, please agree to do it. We will be relying heavily on your help in order to improve the review lag.

Thanks to all of you who completed the JINS Survey; 695 people responded to the readership section. They were almost equally divided among university departments (25\%), medical schools (29\%), and private practice or private hospitals $(32 \%)$. I was encouraged that a majority $(68 \%)$ read at least $75 \%$ of each issue. Regular articles (87\%) and Critical Reviews (74\%) were of greatest interest, but Short Communications, Case Reports, Symposia and Book Reviews were of interest to between $33 \%$ and $53 \%$ of the respondents. The respondents were enthusiastic about the topics $(65 \%)$ and quality $(81 \%)$ of the papers in JINS, but only $46 \%$ felt that papers were published rapidly enough. When asked how JINS could be improved, electronic availability $(66 \%)$ and e-mails with easy access to the Cambridge website for downloading papers $(69 \%)$ were at the top of the list.

Some 175 of the respondents filled out the reviewer section. Of these, $68 \%$ reviewed for JINS regularly, and $85 \%$ felt that the JINS review process was the same or better than other journals. In addition, $89 \%$ to $97 \%$ of these reviewers were pleased with the responsiveness of the Editorial office and the impact of their review on the Editor's final decision.

I was pleased that 236 of the respondents filled out the author section. About half did clinical research with patients, and a smaller percentage characterized their work as cog- nitive neuroscience (28\%) or rehabilitation focused (16\%). Research on adults (49\%) and geriatric populations (30\%) was more common than children (16\%). Fifty-two percent reported that journal impact factor influenced their choice of journals for publication, and when asked the most preferred journal for publication of their work, over $50 \%$ of the respondents listed JINS. The manuscript's topic and journal's reputation were the biggest influences in choice of journal (90 to 94\%), but fairness of editorial decisions, impact rating, and speed of review and publication influenced between 63 and $67 \%$ of the respondents. When authors assessed their last experience when submitting a manuscript to JINS, about $66 \%$ were highly satisfied with the review quality and fairness of editorial decisions, but only $37 \%$ were highly satisfied with the speed of review.

The comments provided by many of the respondents were also helpful. The readership comments reflected the respondents' interests. Some emphasized their preference for papers that were more clinically oriented and others emphasized their preference for papers that were more theoretical and in the realm of cognitive neuroscience. An equal proportion voiced their enthusiastic support for JINS' current focus on theoretically-based, methodologically-sound research with clinical populations. I hope that a renewed emphasis on case studies by instituting a regular Neurobehavioral Grand Rounds Section will partially satisfy those wanting to read papers with a greater clinical emphasis. For the review and authorship sections, the most common suggestions were increased speed and electronic review. The recent advent of online submission is already speeding the review process. In addition, the INS Board of Directors recently voted to publish INS meeting abstracts on the web. This will free about 300 pages per year for publication of peer-reviewed manuscripts, and our publication lag should decrease from nine months to less than six months. That change in itself should increase the number of high quality, theoreticallybased papers that are submitted to JINS. Thanks to all of you who completed the survey.

Dr. Kathleen Y. Haaland JINS, Editor-in-Chief, 2005-2010 New Mexico VA Healthcare System And University of New Mexico

Albuquerque, NM 